\title{
Experience and Understanding of Sensory Neuropathy in the Filipino Context
}

\author{
Constantine L. Yu Chua ${ }^{1}$ and Paul Matthew D. Pasco ${ }^{2}$ \\ ${ }^{1}$ Department of Psychiatry and Behavioral Medicine, College of Medicine and Philippine General Hospital, University of the Philippines Manila \\ ${ }^{2}$ Department of Neurosciences, College of Medicine and Philippine General Hospital, University of the Philippines Manila
}

\begin{abstract}
Background. Locally, understanding and communicating sensory neuropathy may be confounded by a "comprehension gap" during consults and limited "nerve literacy" or knowledge of patients about nerves. This may affect the effectiveness of healthcare.
\end{abstract}

Objective. The study aims to describe the Filipino patients' experience of sensory neuropathy in local terms and their understanding of its causation.

Methods. A cross-sectional, descriptive study among 24 patients with sensory neuropathy was done using semi-structured individual interviews. The first part elicited Filipino terms and descriptions used to explain their experience. The second part elicited perceived cause pre- and post- consult and perceived body part affected.

Results. The most common descriptors of sensory neuropathy include "manhid", "kuryente", "tinutusuk-tusok", "ngalay", "kirot", and "naninigas". Many would initially identify "pasma" as a cause. Post-consult, many would cease to see it as part of natural ageing and would identify structural explanations such as impingement. They would however attribute it to an affectation of "ugat" which most defined as blood vessels.

Conclusion. The abovementioned terms are commonly used to describe sensory neuropathy and can be clinically useful in eliciting symptoms. There is existing confusion with regards to the nerve as a structure involved even after consultation.

Key Words: sensory neuropathy, nerve literacy, Filipino

\section{Introduction}

Sensory neuropathy is a pathology present in diseases of varied etiologies. It is a complicated experience composed of diverse but distinct symptoms, and may be difficult to discuss in clinical encounters for both patients and clinicians. However, it is a very important concern in diagnosis,

Presented and won second place at Annual Medical Interns' Research Symposium, 2014, UP-PGH.

Corresponding author: Constantine L. Yu Chua, MD

Department of Psychiatry and Behavioral Medicine

Philippine General Hospital

University of the Philippines Manila

Taft Avenue, Ermita, Manila, 1000 Philippines

Telephone: +632 5548400 local 2436

Email: constantineyuchua@gmail.com management, and prognostication. For example, the specific character of sensory symptoms can be diagnostic such as in differentiating small versus large nerve fiber involvement. ${ }^{1}$ Furthermore, sensory neuropathy symptoms were found to be correlated with decreased physical and mental quality of life, while a positive neuropathy screening test alone was not., However, it is underrecognized and undertreated in primary care practice, and standard antidepressant or anticonvulsant treatment is underutilized. . $^{3,4}$ This may reflect failure to assess symptoms accurately, which requires exploration to identify if it is neuropathic or otherwise. ${ }^{5}$ Prognosis-wise, sensory neuropathy has been found to be the 3rd most significant risk factor leading to amputation in persons with a diabetic foot ulcer locally, ${ }^{6}$ and thus would have to be detected promptly.

A patient's awareness and understanding of sensory neuropathy affects the timing in which they would report symptoms, if at all, and how they would respond to it as a condition. The term "stroke literacy" was used in literature to describe the degree in which persons understand stroke. In this study, only $53.7 \%$ of respondents had a correct idea of its causation. ${ }^{7}$ There has yet been no similar study done internationally or locally for "neuropathy literacy" or "nerve literacy".

On the side of clinicians, a good understanding of terminologies used would impact how they would elicit and understand patients' neuropathy. There have been foreign studies based on the terminologies used by patients to describe sensory neuropathy. For example, the Michigan Neuropathy Screening Instrument (MNSI) has a 15-point questionnaire listing symptoms of sensory neuropathy in established English terms. It used terms like "numb", "burning", and "prickling". 8 Although the Philippines is a bilingual nation, using English terms or attempted translations is not expected to be that simple or effective. An African study illustrates this dilemma. It was found that there was a "comprehension gap" in the way patients described their experience of sensory neuropathy. For example, 20\% of patients voluntarily reported loss of sensation in the feet or hands in the local language but only $20 \%$ of them equated it to the term "numb". The same patients did not use vernacular terms for "tingling", "electric-like", and "shooting" when asked an initial open-ended question, but identified it as present when enumerated an English list of symptoms. As a form of counterchecking, they were asked to translate those English terms into the African vernacular. Their translations were assessed by the authors to actually mean something different. ${ }^{9}$ 
The patient being able to recognize and report sensory neuropathy symptoms and the clinician's ability to comprehend and elicit these symptoms promptly and educate his or her patient will dictate a successful clinical encounter. In this light, this study is a preliminary study on how Filipinos understand and describe their experience of sensory neuropathy. Specifically, the study aims to describe the experience of sensory neuropathy using locally accepted and culturally appropriate terms and the Filipino patients' understanding of the causes of sensory neuropathy.

\section{Methods}

The study followed a cross-sectional, descriptive, interview-based qualitative design. Data gathering lasted one month and no further follow-up was done.

\section{Participants and Screening}

Adult patients from the internal medicine, neurology, and rehabilitation medicine clinics of the Philippine General Hospital Outpatient Department (PGH-OPD) diagnosed with sensory neuropathy and who had Filipino as their primary language were personally recruited by the investigator in the waiting area. Three major diagnostic groups were represented: 1) mononeuropathy such as carpal tunnel syndrome, 2) radiculopathy, and 3) diffuse neuropathy such as diabetic neuropathy. Purposive sampling was done to obtain a balanced representation of diagnoses. Interviews were conducted to the point of redundancy of answers which yielded eight patients per diagnostic group.

Patients both with formal electromyography and nerve conduction velocity (EMG-NCV) studies and without were included. This allowed a broader spectrum of patients to be examined since many cases are not usually referred for EMC-NCV as it is costly and requires a separate clinic visit. ${ }^{10}$ To validate neuropathy for patients without EMG-NCV, Semmes Weinstein Monofilament Testing (5.07/10g) was performed. This tool has been found to be $96 \%$ specific in ruling in neuropathy if a patient gets 3 or less correctly out of 8 tries. ${ }^{8}$ Exclusion criteria included patients who have central nervous system, cutaneous, and musculoskeletal lesions including stroke, non-healing ulcer, severe calluses, and amputation to avoid confusion with nociceptive or central types of sensory disturbance. Patients who are healthcare professionals or students thereof were disqualified to avoid skewing of results.

\section{Data Collection}

The selected patients were administered a set of semistructured questions with the first part focusing on their experience and the second on their perceptions.

The first part involved an open-ended question regarding what sensory disturbances the patients feel. They were asked to give either specific terms or descriptions to describe the experience. Patients were then asked to define their given terms or inversely, to volunteer terms to label their descriptions. The goal of this was to compile a list of terms with corresponding definitions.

The second part was divided into two sub-parts. The first included an open-ended question as to what the patient first felt was the cause of his symptoms upon its onset (preconsult) and what he knows as the cause now (post-consult). The second involved the patient describing which part of his body is affected and is creating the symptoms. As much as possible, they were given follow-up questions to elicit specific tissues such as bones, arteries, veins, nerves, ligaments, skin, muscles, and the like as against anatomic regions such as hands or feet. The goal of this was to make a list of the perceived causes of sensory neuropathy before and after consult as well as a list regarding what body part they ascribed symptoms to.

\section{Data Analysis}

Answers were transcribed verbatim. For the first part, answers were collated and a tally was made with emphasis on noting multiple definitions for same terms and also descriptions with no terminologies given. For the second part, answers with the same themes were grouped together and tallied, but specific answers under each theme were still noted.

\section{Ethical Considerations}

The study was approved by the Research Ethics Board (REB) of the University of the Philippines Manila (UPM) and the Expanded Hospital Research Office (EHRO) of the Philippine General Hospital (PGH). The principal investigator has no conflicts of interest and is not affiliated with any sponsor.

\section{Results}

\section{Patient Profile}

Respondents were mostly in middle adulthood with varied types of work and educational attainment. Approximately half of the patients have undergone EMGNCV, physical therapy or occupational therapy (PT/OT), and have tried traditional therapies. Around two-thirds of the respondents were taking some form of medication for the nerves, the most common of which is vitamin B supplementation (Table 1).

\section{Experience of Sensory Neuropathy}

Table 2 is a glossary made from the respondents' answers. Volunteered terms were used as headings. The descriptions which the respondents themselves gave to define their own terms were put under them. Terms which the respondents were no longer able to define or descriptions which respondents could not give a specific term to were also noted. 
Table 1. Patient Characteristics ( $\mathrm{N}=24)$

\begin{tabular}{|c|c|}
\hline \multicolumn{2}{|l|}{ Demographic Data } \\
\hline Mean Age (years) & $56.8 \pm 11.9$ \\
\hline Sex $(M: F)$ & 8:16 \\
\hline \multicolumn{2}{|l|}{ Type of work } \\
\hline Professional / supervisory & 3 \\
\hline Manual labor & 14 \\
\hline Homemaker / unemployed & 7 \\
\hline \multicolumn{2}{|l|}{ Educational attainment (total, undergraduate:graduate) } \\
\hline Elementary level & $5,2: 3$ \\
\hline High school level & $10,4: 6$ \\
\hline Vocational course & $2,0: 2$ \\
\hline College level & $6,3: 3$ \\
\hline Post graduate level & $1,0: 1$ \\
\hline \multicolumn{2}{|l|}{ Diagnoses } \\
\hline \multicolumn{2}{|l|}{ Peripheral Mononeuropathy } \\
\hline Acute traumatic nerve injury & 2 \\
\hline Non-traumatic & 6 \\
\hline Radiculopathy & 8 \\
\hline Diffuse neuropathy (diabetes) & 8 \\
\hline \multicolumn{2}{|l|}{ Medical History } \\
\hline & Yes \\
\hline Electromyography - Nerve Conduction Velocity Study & 11 \\
\hline Nerve-related medication (vit. B, pregabalin/gabapentin) & 15 \\
\hline Physical therapy or occupational therapy (PT/OT) & 11 \\
\hline Traditional therapy (hilot, albularyo, etc.) & 11 \\
\hline
\end{tabular}

Table 2. Descriptions of Sensory Neuropathy (Frequency in Percentage, \%)

\begin{tabular}{|c|c|c|c|}
\hline & "Manhid" & & 91.7 \\
\hline \multirow{8}{*}{ Definitions } & Makapal ang pakiramdam & 45.8 & \\
\hline & Bawas ang pakiramdam & 33.3 & \\
\hline & Tinutusuk-tusok & 20.8 & \\
\hline & Parang may kuryente & 12.5 & \\
\hline & Parang may buhanging nakadikit & 8.3 & \\
\hline & Walang malay ang bahagi & 4.2 & \\
\hline & May kumakalat na di kumportable pag nadampian & 4.2 & \\
\hline & Punung-puno ang pakiramdam & 4.2 & \\
\hline & "Kuryente" & & 29.2 \\
\hline \multirow{3}{*}{ Definitions } & Nakakagulat na "ground" (na di matukoy kung saan) & 16.7 & \\
\hline & Gumagapang na "ground" & 12.5 & \\
\hline & Parang may mga langgam & 4.2 & \\
\hline & "Tinutusuk-tusok" & & 20.8 \\
\hline \multirow{4}{*}{ Definitions } & Parang may mga tinik-tinik & 8.3 & \\
\hline & Mala-kuryenteng pumipitik-pitik & 4.2 & \\
\hline & Tumutusok na masakit & 4.2 & \\
\hline & Parang tinutusokng tansan & 4.2 & \\
\hline & "Ngalay" & & 12.5 \\
\hline \multirow{2}{*}{ Definitions } & Pagod na di maalis kahit ipahinga / di ginagamit & 8.4 & \\
\hline & Parang mabibitawan ang gamit & 4.2 & \\
\hline & "Naninigas" & & 12.5 \\
\hline & "Makirot" & & 12.5 \\
\hline & "Mabigat" & & 8.3 \\
\hline \multirow{5}{*}{$\begin{array}{l}\text { Description } \\
\text { s with no } \\
\text { specific } \\
\text { term } \\
\text { identified }\end{array}$} & Parang mainit na uri ng kirot & & 8.3 \\
\hline & Parang binabaligtad, umiigsi, o binabaluktot & & 4.2 \\
\hline & Parang may hawak na yelo & & 4.2 \\
\hline & Masakit kapag nadidiinan & & 4.2 \\
\hline & Nakakagising na sakit & & 4.2 \\
\hline
\end{tabular}

"Manhid" was volunteered as a term by almost all respondents, with "makapal ang pakiramdam", "bawas ang pakiramdam", "tinutusuk-tusok" and "parang may kuryente" as its most common definitions. The second most frequent term used is "kuryente" which was described as "ground" of two types: "nakakagulat" or "gumagapang".
This is followed by "tinutusuk-tusok" which some patients identified as a stand-alone term distinct from "manhid". "Ngalay", "naninigas" and "makirot" are other terms used by respondents but were deemed too basic to further define.

\section{Understanding of Causation}

The most common initial perception of causation was "pasma" which was found among seven respondents across the diagnostic subgroups (Table 3). Four respondents had no initial idea regarding causation. Three attributed it to overwork and two to ageing. An unforeseen initial perception from two respondents was the thought that the sensory problems were iatrogenic, resulting from procedures such as internal fixation and not from the trauma itself. Post-consult, there was a change in beliefs from that before the consult. There was a general shift to medical or structural explanations such as diabetes, which was found in $100 \%$ of that group, and impingement which was found in five out of eight in the radiculopathy group. There was also a shift from natural to pathologic causation. For instance, respondents who initially answered "ageing" both changed their perception post-consult.

Table 3. Pre- and Post- Consult Perceptions on Causation

\begin{tabular}{|c|c|c|}
\hline & Pre-consult & Post-consult \\
\hline \multicolumn{3}{|l|}{ Non-traumatic mononeuropathy $(\mathrm{n}=6)$} \\
\hline Overuse* $^{*}$ & 1 & 3 \\
\hline Impingement* & 0 & 1 \\
\hline Pasma & 3 & 2 \\
\hline Ageing & 2 & 0 \\
\hline \multicolumn{3}{|l|}{ Acute traumatic mononeuropathy $(\mathrm{n}=2)$} \\
\hline Iatrogenic & 2 & 1 \\
\hline Prolonged position & 0 & 1 \\
\hline Injury per $\mathrm{se}^{*}$ & 0 & 0 \\
\hline \multicolumn{3}{|l|}{ Radiculopathy (n=8) } \\
\hline Impingement* & 0 & 5 \\
\hline Pasma & 2 & 0 \\
\hline No idea & 2 & 0 \\
\hline Pinasok ng hangin & 1 & 0 \\
\hline Overuse & 2 & 2 \\
\hline Combination of pasma and lamig** & 1 & 1 \\
\hline \multicolumn{3}{|l|}{ Diffuse Neuropathy $(\mathrm{n}=8)$} \\
\hline Diabetes* & 2 & 8 \\
\hline Pasma & 1 & 0 \\
\hline No idea & 2 & 0 \\
\hline Napangamuyan ${ }^{* * *}$ & 1 & 0 \\
\hline Rheumatism & 1 & 0 \\
\hline
\end{tabular}

\section{Nerve Literacy}

Eighteen respondents (75\%) answered the term "ugat". Eleven of these equated it to blood vessels. Three were noted to have answered that "ugat" were nerves, but still defined it as blood vessels when asked a follow-up on what nerves are. Only two respondents identified "ugat" as nerve and defined it correctly. Five respondents believed it was a generalized affectation of all the tissues of the part or the body (Table 4). 
Table 4. Perceived Affected Body Part Causing Symptoms

\begin{tabular}{lr}
\hline "Ugat" & 11 \\
As blood vessels & 1 \\
As both blood vessel and sensorimotor tissue & 3 \\
As "nerves", but defined as blood vessels & 1 \\
As nerves, then defined as "energy channels" in the body & 2 \\
As nerves, then defined as serving sensorimotor functions & 1 \\
"Litid" defined as a ligament & 1 \\
"Likod" or the back per se & 3 \\
The whole hand (no specified part) & 1 \\
The whole body &
\end{tabular}

\section{Discussion}

\section{Experience of Sensory Neuropathy}

It is notable in the compilation that terms were both multidimensional and overlapping. For example, "manhid" is a familiar and thus useful term but there were two aspects to which respondents defined it: sensory blunting and tingling sensation. These represent very different experiences with varying implications. "Tinutusuk-tusok" sometimes fell under "manhid" but some deemed it a distinct experience. The tingling sensation of "kuryente" can also fall under manhid, but "kuryente" can also involve a unique characteristic approximating "shooting pain". The richness and ambiguity of terminologies should lead the clinician to both triangulate by using overlapping terms and to dissect terminologies with follow-up questions. Most importantly, the Filipino clinician should not attempt to force direct translations from medical textbooks as this would lead to the unwanted "comprehension gap".

\section{Understanding of Causation}

In the interviews, "pasma" seems to be considered by respondents as a wrong response to overwork such as washing their hands or feet immediately without rest. None of those who answered "pasma" recounted an experience of tremors, which is one version of the folk descriptions of the concept. "Pasma" in the study appeared to deal mainly with two factors: 1) overwork and 2) consequent exposure. Pasma can thus be a useful term to elicit a habit of overuse, but there should be an effort from the clinician to emphasize the overuse aspect and dissociate it from the exposure aspect.

Related to this, it was observed that many respondents initially focused on behaviors such as "pasma" or overuse to explain symptoms. Explanations that focus on anatomical or structural constructs were rare at the start. This focus on behavior may be advantageous when trying to advise lifestyle modifications. However, patients may find it hard to realize that neuropathy may persist even upon stopping the causative behavior. Also, it may serve as a barrier in explaining need for procedures such as release surgery. It should be noted though that currently, this focus on purely behavioral explanations is addressed by clinicians during encounters as shown in the post-consult results. They are also able to educate patients that sensory neuropathy is not natural, such as an effect of normal ageing, but is a pathologic process.

An issue that arose was that of iatrogenesis in trauma patients. This may be because neuropathic symptoms mostly arise during the recuperation period. During the interval between injury and surgery, sensory neuropathy may be masked due to acute inflammation and pain. This highlights the importance of discussing the possibility of nerve injury and as a prerequisite, the nerve concept, before any procedure is done to avoid liability. To emphasize this point, attention is given to the respondent who still believed that his sensory neuropathy was caused by surgical intervention even after several consults with different doctors.

\section{Nerve Literacy}

The fact that only two respondents correctly identified and understood the nerve concept shows that many patients may undergo diagnostics and management and still not understand the structural cause of their symptoms. A closer look at the profiles and interview transcripts of the two who answered correctly was done. The type of diagnosis and having undergone EMG-NCV, formal therapy, or prescription of nerve-related medication were not seen to have any effect on "nerve literacy". In fact, these factors were heterogenous among the two. What was noted was that both respondents, as against many other respondents, were college graduates. There is a possibility that "nerve literacy" may be more established at that level, although some other college-level respondents still made mistakes. What may account for this is the lack of a vernacular term and integration into lay culture. To illustrate, there was an apparent confusion with the ambiguous term "ugat" which was defined by many as blood vessel rather than as a nerve. In contrast, there was only minimal interchanging with joint, bone, muscular, or integumentary pathology as a cause of the symptoms because there are distinct vernacular terms for these. The sociolinguistic barrier being left unaddressed may also reflect some limitation with basic health education in the primary and secondary levels. In fact, the study shows that even learning the term "nerve" does not mean it is automatically understood.

\section{Conclusion and Recommendations}

The first goal of the study is to describe the experience of sensory neuropathy in locally relevant terms. Putting together the most common answers of the respondents, the Filipino experience of sensory neuropathy can be summarized as an experience of "manhid", "kuryente", "tinutusuk-tusok", "ngalay", "naninigas", and "makirot".

For interviews, culturally appropriate questions that can be asked include those listed below. It is summarized in the mnemonic "KaMay Na КаТаKа-ТаКа", which may also connote the complexity of the sensory neuropathy experience. Note that "kuryente" was used twice to reflect 
its two facets, and to include the tingling aspect of "manhid".

- MaKapal ba ang pakiramdam?

- $\quad$ Parang Manhid ba ang bahagi?

- $\quad$ Ngalay ba ang pakiramdam ng kamay o paa?

- Parang may Kuryente ba na gumagapang?

- Parang Tinutusok ba?

- Parang may Kuryente ba na pumipitik o nakakagulat?

- Para bang matigas o naninigas?

- $\quad$ May kasama bang Kirot?

The second goal is to describe Filipino patients' understanding of causation in sensory neuropathy. Most patients would initially focus on behaviors as a cause with "pasma" being the most common followed by overuse and ageing. After consultation, structural explanation such as impingement was noted and patients no longer attributed the condition to natural ageing. Many patients would think of "ugat", defined as blood vessels, as the cause of their symptoms despite undergoing several consults and related procedures or medications.

Upon reviewing the findings of the study, some strategies and recommendations include:

- "Pasma" can be used by clinicians to elicit the habit of overuse in history taking. It can be reframed as something that warrants medical consultation instead of a natural occurrence. It is not critical to debunk "pasma" but the role of exposure to cold should be deemphasized.

- Continue to stress behavioral causes such as overwork but make sure to introduce and explain structures to avoid possible difficulty when discussing management and prognosis.

- Continue the emphasis that sensory neuropathy it is not part of natural ageing and is a pathologic condition.

- For patients with possible but still undetected neuropathy such as in acute trauma, effort should be given to explain its nature to avoid any liability.

- Avoid using the term "ugat" without any modifiers or explanations. Emphasis may be given to differentiating nerves from blood vessels, which is the most common misconception. Visual aids may potentially help.

- For the long term, basic or secondary education inclusion of nerve literacy is suggested. This is especially important because overuse mononeuropathies and other complications tend to affect manual laborers who have not reached college.

- A local term for the nerve concept can also be developed, studied, and disseminated to integrate nerve literacy into lay culture.

The study, having been done in the hospital setting, may be subject to some degree of selection bias because there was a tendency for persons with more severe affectation, more established health-seeking behaviors, and less traditional beliefs to be recruited. Some recall bias may have also occurred for patients who have imbibed terms and explanations used by their clinicians and fail to accurately delineate pre-consult and post-consult beliefs. However, these do not negate the utility of the study as a preliminary exploratory endeavor. The study may be expanded to involve persons in the community or to be a longitudinal one in the future.

Recommended follow-up studies include the formation and validation of an interview-based screening tool using the glossary or mnemonic made in the study with EMGNCV as a gold standard. The effect of educational interventions based on this study's findings on promptness of consult or compliance in patients with sensory neuropathy can also be studied.

\section{Acknowledgments}

The authors would like to thank Prof. Nina Castillo-Carandang for her invaluable input regarding the methodologies of a qualitative research and the consultants and residents of the Departments of Neurosciences, Rehabilitation Medicine, and Internal Medicine for their permission to interview patients consulting in their offices.

\section{Statement of Authorship}

All authors have approved the final version submitted.

\section{Author Disclosure \\ All the authors declared no conflicts of interest.}

\section{Funding Source}

This paper was funded by personal funds.

\section{References}

1. Willison HJ, Winer JB. Clinical evaluation and investigation of neuropathy. J Neurol Neurosurg Psychiatry. 2003; 74 Suppl 2:ii3-ii8.

2. Kulkantrakorn K, Lorsuwansiri C. Sensory profile and its impact on quality of life in patients with painful diabetic polyneuropathy. J Neurosci Rural Pract. 2013; 4(3): 267-70.

3. Van Acker K, Bouhassira D, De Bacquer D, et al. Prevalence and impact on quality of life of peripheral neuropathy with or without neuropathic pain in type 1 and type 2 diabetic patients attending hospital outpatients clinics. Diabetes Metab. 2009; 35(3):206-13.

4. Haanpää ML, Backonja MM, Bennett MI, et al. Assessment of neuropathic pain in primary care. Am J Med. 2009; 122(10 Suppl):S13-21.

5. Krause SJ, Backonja MM. Development of a neuropathic pain questionnaire. Clin J Pain. 2003; 19(5):306-14.

6. Cardino MJT, Josol CV, Isip-Tan I, Jimeno C. Risk factors for major amputation of diabetic foot ulcers. Philipp J Intern Med. 2011; 49(2):74-7.

7. Willey JZ, Williams O, Boden-Albala B. Stroke literacy in Central Harlem: A high-risk stroke population. Neurology. 2009; 73(23):1950-6.

8. Al-Geffari M. Comparison of different screening tests for diagnosis of diabetic peripheral neuropathy in Primary Health Care setting. Int J Health Sci. 2012; 6(2):127-34.

9. Shaikh A, Bentley A, Kamerman PR. Symptomatology of peripheral neuropathy in an African language. PLoS One. 2013; 8(5):e63986.

10. Perkins BA, Olaleye D, Zinman B, Bril V. Simple screening tests for peripheral neuropathy in the diabetes clinic. Diabetes Care. 2001; 24(2):250-6. 